\title{
Adaptive Behavioral Outcomes: Assurance Of Learning And Assessment
}

David S. Baker, University of Louisiana at Lafayette, USA Geoffrey T. Stewart, University of Louisiana at Lafayette, USA

\begin{abstract}
Business schools are currently being criticized for lacking relevance to the applied working environment in which students are supposed to be prepared to make immediate contributions and reasoned independent decisions in a fluidly changing market (Haskell and Beliveau, 2010, and Michlitsch and Sidle, 2002). While technical skills (accounting, marketing, finance, etc.) have comprised the core of traditional course subject matter, today's businesses also need graduates who arrive to work possessing integrative skills such as adaptable decision-making in changing competitive environments.
\end{abstract}

Teaching and assessing integrative adaptive behavioral outcomes is both a break from the norm and a challenge to those tasked with developing assessment standards and rubrics. Discussing the demand for developing and assessing adaptive learning skills in business schools is the easy part. Incorporating the development of these non-technical skills into curricula or programs of learning requires one to identify specific skills that require adaptive improvement, design specific pedagogy to develop the skills, and longitudinally measure student performance. In reality, many business curricula lack learning environments where integrative non-technical skills such as longitudinal adaptive behavior can be isolated and programmed for improvement.

This manuscript identifies an experiential inductive-based teaching method that has been extended to account for longitudinal variation in adaptive behavior-based learning. It describes a holistic course pedagogy that builds on traditional theoretical knowledge, but then requires students to actively apply that knowledge using interdisciplinary decision-making that receives ongoing competitive market feedback. An assessment rubric is also suggested for linking to important AACSB Assurance-of-Learning objectives targeted at measuring behavioral-based outcomes related to applied adaptive decision-making behavior. Finally, methods are suggested in which adaptive behavioral outcomes can be integrated into other forms of more traditional pedagogy.

Keywords: Adaptive; Behavior; Assessment; Accreditation; Assurance-of-Learning

\section{INTRODUCTION}

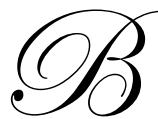

usiness schools are currently being criticized for lacking relevance to the applied working environment in which students are supposed to be prepared to make immediate contributions and reasoned independent decisions in a fluidly changing market (Haskell and Beliveau, 2010, and

Michlitsch and Sidle, 2002). While technical skills (accounting, marketing, finance, etc.) have comprised the core of traditional course subject matter, today's businesses also need graduates who arrive to work possessing integrative soft-skills such as interpersonal communication, teamwork, competitiveness, and adaptable decision-making in competitive environments.

In an era of mounting assurance-of-learning assessment in business schools, teaching and assessing integrative adaptive soft-skills is both a break from the norm and a challenge to those tasked with developing assessment standards and rubrics. Discussing the demand for developing and assessing soft-skills in business schools is the easy part. Incorporating the development of these non-technical skills into curricula or programs of 
learning requires one to identify specific skills that require adaptive improvement, design specific pedagogy to develop the skills, and longitudinally measure student performance. In reality, many business curricula lack learning environments where integrative non-technical soft-skills such as longitudinal adaptive behavior can be isolated and programmed for improvement.

\section{BACKGROUND AND SCOPE}

This manuscript focuses on the assessment of student abilities to compete and adapt decision-making in a rapidly changing market environment that contains both controllable and uncontrollable variables. The primary research question asks "how does one ensure student learning related to adaptive behavioral-based decision-making outcomes in a fluidly changing competitive market environment?" Adapted from Clarke (2009), adaptive behavior is defined as evidence of targeted longitudinal change in a decision maker's mental models through active observation of the consequences of actions. The research question is important because traditional marketing classes often use pedagogy like lecture, case study, video cases, discussion, projects and presentations. These methods do not extend learning beyond a mostly static knowledge application realm of assessment. Assessment of actual adaptive learning behavior related to longitudinal application of that knowledge is therefore limited using these tools. However, an experiential-based teaching method (Prince and Felder, 2006) can be extended to account for the assessment of certain adaptive behavioral outcomes. Table 1 defines adaptive behavior and its assessment.

Table 1: Adaptive Behavior Definition and Assessment

\begin{tabular}{|l|l|l|}
\hline \multicolumn{1}{|c|}{ Skill Assessed } & \multicolumn{1}{|c|}{ Definition } & \multicolumn{1}{c|}{ How it is assessed } \\
\hline Adaptive Behavior & $\begin{array}{l}\text { Evidence of targeted longitudinal change in a } \\
\text { decision maker's mental models through active } \\
\text { observation of the consequences of actions } \\
\text { (adapted from Clarke 2009) }\end{array}$ & $\begin{array}{l}\text { Adaptation of Strategic and/or Tactical Decisions } \\
\text { Improved Management Performance (over multiple } \\
\text { decision rounds) } \\
\text { Improved Marketing Performance (over multiple } \\
\text { decision rounds) } \\
\text { Improved Financial Performance (over multiple } \\
\text { decision rounds) }\end{array}$ \\
\hline
\end{tabular}

An increasing number of instructors are using computer-based simulations as supplemental learning tools which focus on applied behavioral learning objectives. Introduced in 1956 by the American Management Association (Cohen and Rhenman, 1961), business simulations have grown substantially in business schools over the last 10-15 years. Research has shown that students perceive simulations as being 1) engaging, 2) useful, 3) effective learning tools, and 4) effective in promoting teamwork (Lainema and Lainema, 2007). As noted by Clarke (2009), business simulations are particularly suited to operationalize theoretical knowledge into experiential knowledge (Anderson and Lawton, 2004; 2009), adaptable decision-making (Cadotte, 1995), adaptable learning (Aldrich, 2005, and Senge, 1995), and behavioral, attitudinal, and cross-functional knowledge change (Sherpereel, 2005).

\section{Incorporating Adaptive Behavioral Outcomes into Course Embedded Assessment}

Most important to the pedagogical advancement proposed in this paper, a computer-based simulation used within a specific context can assess adaptive behavior related to longitudinal decision-making in a competitive business environment. It is this very context that makes simulations unique. Assessing longitudinal adaptive behavior is inherently difficult to replicate using other types of pedagogy. Finally, related to linking course teaching objectives to assurance-of-learning in accreditation assessment, this manuscript also suggests an assurance-oflearning rubric related to AACSB assessment of adaptive behavior in a competitive environment.

At the undergraduate level and particularly at the graduate level of study, students increasingly have work experience and are aware of the need for higher order applied adaptive decision-making in a cross-functional competitive environment. However, traditional pedagogy is limited in its ability to provide a competitive interdisciplinary environment that includes experiential-based adaptive decision-making outcomes. Students understand they will be expected to compete in a global marketplace and they also understand that learning and communication 
in the "real world" extends beyond textbooks, written reports, and static exams of knowledge. Beyond traditional teaching pedagogy, there is a higher order of applied inductive thinking that requires one to critically apply technical knowledge longitudinally into a competitive market environment. This requires integrative, adaptable behavior and decision-making skills. This manuscript outlines one way in which this level of higher order adaptive behavioralbased thinking can be incorporated into the marketing classroom.

Analysis Papers

Case Study

Video

Discussion

Business Planning

Market Planning

Service Based Learning

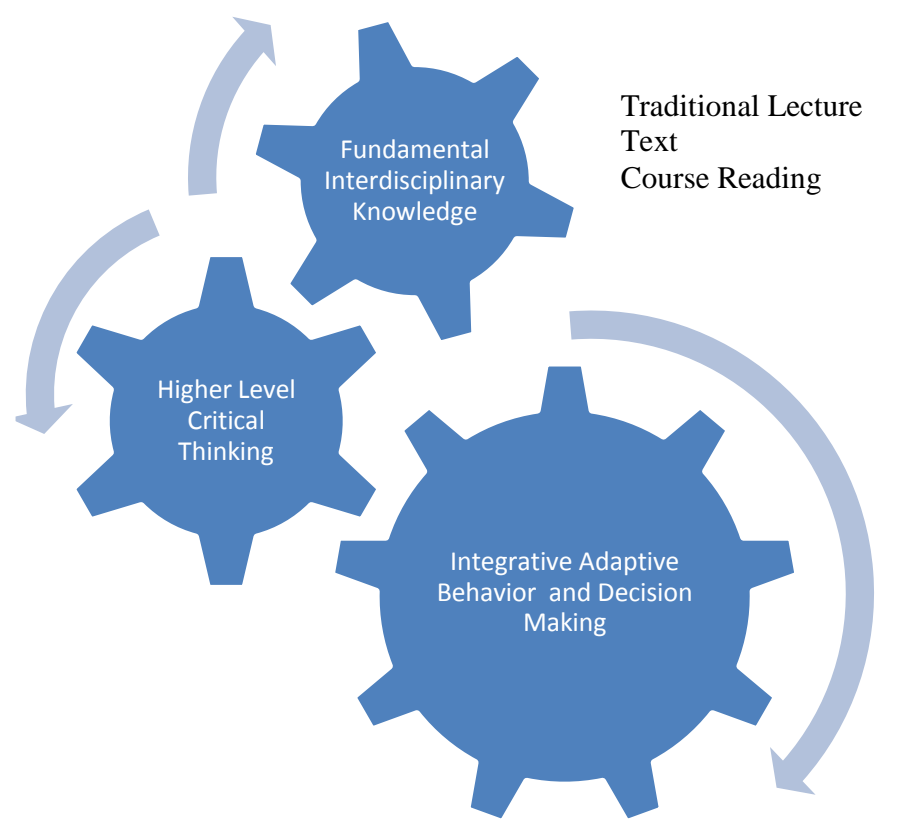

Figure 1: Pedagogical Positioning
Competitive Simulation within a longitudinally changing market environment

Figure 1 illustrates the pedagogical positioning of adaptive behavior within the context of building knowledge pedagogically first through fundamental theoretical knowledge, then further through critical thinking methods, and ultimately building to integrative applied adaptive behavior. This manuscript proposes an approach to assessing adaptive behavioral development by creating a business environment via competitive computer-based simulation requiring students to strategically plan for controllable business forces. However, it also requires students to longitudinally adapt to uncontrollable competitive environmental forces within their decision-making process.

As with many simulations, students are required to compete against each other or simulated competitors in a business marketing context. The learning outcomes for this exercise are predicated on the need to operationalize static, theoretical knowledge from text and lecture into informed decisions which enable their firm to effectively compete in a longitudinally changing marketplace. This type of inductive teaching method helps faculty ground theory in applied behavioral outcomes by allowing students to experience the results of their decision-making longitudinally; thereby allowing them to adapt their behavior in successive decision-making rounds (Prince and Felder, 2006).

The student is provided with a case study and a student decision-making guide provided by the simulation provider. In addition, traditional pedagogy is integrated into the overall course design using lecture and course material related to strategic marketing planning and balanced scorecard theory into the buildup to the beginning of the simulation. The simulation experience is graded using a three tiered assessment to fully achieve the desired learning outcomes. First, each student receives a grade for their competitive performance in the simulation itself. Second, student groups are required to prepare a comprehensive shareholder report that links to the general structure and content of shareholder reports in publically traded institutions. Third, students are required to complete 
individual-based learning outcome papers that elicit them to critically assess and apply what they have learned from the simulated environment to what they experience or see in the actual business environment.

When used effectively, simulation-based adaptive behavioral outcomes are integrated into a holistic course grading rubric to assure integration of the exercise into an integrative pedagogy for the entire course. Using an undergraduate International Marketing course as a basis, Table 2 identifies adaptive behavioral-based learning outcomes that would otherwise be difficult to attain without the use of a competitive simulation as an integrative pedagogical tool. It also provides an example of an integrative course grading rubric utilizing all three levels of pedagogy illustrated previously in Figure 1.

Table 2: Pedagogical Objectives and Suggested Integrative Course Assessment Rubric

Pedagogical objectives of adaptive competitive engagement through integrative simulation

Competitive application of knowledge of strategic international marketing theory such as channel strategy, adaptive segmentation, targeting, pricing strategy, and competitive innovation management.

Competitive application of marketing research for brand development, implementation, and adaptation for international markets.

Applied strategic marketing planning and adaptive strategic planning in a fluidly competitive business environment.

Applied cross-cultural adaptation to environmental scenarios related to consumption, product preferences, cultural values, and perception of products and advertising.

Applied competitive engagement of text-based theory in a fluidly changing interdisciplinary decision-making organizational environment.

Adaptive management decision-making and market-based feedback requiring interdisciplinary understanding of accounting, production, and finance activities.

\begin{tabular}{|c|c|c|}
\hline 3 Exams @ 100 points each (Lecture and Text-Based) & 300 points & $60 \%$ \\
\hline Computer Simulation Competition & 75 points & $15 \%$ \\
\hline Group Simulation Shareholder Report & 50 points & $10 \%$ \\
\hline Individual Simulation Learning Outcome Analysis Paper & 50 points & $10 \%$ \\
\hline Peer Reviews of Group Participation & 25 points & $5 \%$ \\
\hline Total & 500 points & $100 \%$ \\
\hline
\end{tabular}

\section{Assurance of Learning and Assessment}

This manuscript extends traditional business simulation assessment by integrating adaptive behavioralbased learning objectives into a holistically designed course pedagogy. Teaching and assessment of adaptive behavior is important because it captures activities involved in the longitudinal evaluation and control portions of the marketing planning process. In addition to the pedagogical advancement gained from using a competitive market simulation within this context, it is also possible to achieve AACSB Assurance-of-Learning accreditation objectives related to applied adaptive behavioral outcomes. Table 3 suggests an acceptable AACSB Assurance-of-Learning rubric for evaluation of behavioral-based outcomes utilizing a competitive business marketing simulation.

As noted by Haskell and Beliveau (2010), newly implemented AACSB standards require that schools use direct measures of assessment in student learning objectives. For example, students must be able to demonstrate knowledge. Traditionally, this has been done through written deliverables such as examinations and written papers. However, behavioral outcomes such as longitudinal competitive engagement, decision-making, and adaptive application of theory are difficult to assess using these methods. Specifically, by effectively using balanced scorecard and other cumulative key performance metrics, it is possible to quantitatively assess longitudinal behavioral outcome achievement of specific learning objectives. For example, one way to do this is by assessing a comprehensive performance measure of the number of students that are able to achieve a positive cumulative total shareholder return at the end of the simulation. Another way is to use comparative class level balanced scorecard achievement metrics related to financial, customer, process, and learning and growth within the course of the simulation. 
Table 3: Suggested AACSB Assurance of Learning Rubric

\begin{tabular}{|c|c|c|c|c|c|}
\hline \multicolumn{6}{|c|}{ Adaptive Behavior Rubric } \\
\hline & 1Weak & 2 Needs to Improve & 3 Effective & 4 Very Effective/Strong & Score \\
\hline $\begin{array}{l}\text { Adaptation of } \\
\text { Strategic } \\
\text { and/or } \\
\text { Tactical } \\
\text { Decisions }\end{array}$ & $\begin{array}{l}\text { Decisions have } \\
\text { not changed from } \\
\text { one decision } \\
\text { round to the next. }\end{array}$ & $\begin{array}{l}\text { Modifications to } \\
\text { decisions have been } \\
\text { made but do not result } \\
\text { in positive } \\
\text { improvement in } \\
\text { business performance }\end{array}$ & $\begin{array}{l}\text { Modifications to } \\
\text { decisions have created } \\
\text { positive improvement in } \\
\text { business performance but } \\
\text { have not established } \\
\text { competitive advantage }\end{array}$ & $\begin{array}{l}\text { Modifications to decisions } \\
\text { have created positive } \\
\text { improvement in business } \\
\text { performance and have } \\
\text { established competitive } \\
\text { advantage }\end{array}$ & \\
\hline $\begin{array}{l}\text { Improved } \\
\text { Marketing } \\
\text { Performance }\end{array}$ & $\begin{array}{l}\text { Marketing } \\
\text { effectiveness has } \\
\text { not changed over } \\
\text { the course of the } \\
\text { game. }\end{array}$ & $\begin{array}{l}\text { Marketing } \\
\text { effectiveness has } \\
\text { varied over the course } \\
\text { of the game but has } \\
\text { not established a } \\
\text { positive trend. }\end{array}$ & $\begin{array}{l}\text { Marketing effectiveness } \\
\text { has increased in a } \\
\text { positive direction over } \\
\text { the course of the game } \\
\text { but has not exceeded that } \\
\text { of the competition. }\end{array}$ & $\begin{array}{l}\text { Marketing effectiveness } \\
\text { has increased in a positive } \\
\text { direction over the course } \\
\text { of the game and has } \\
\text { exceeded that of all } \\
\text { competitors. }\end{array}$ & \\
\hline $\begin{array}{l}\text { Improved } \\
\text { Financial } \\
\text { Performance }\end{array}$ & $\begin{array}{l}\text { Financial } \\
\text { performance has } \\
\text { continuously } \\
\text { decreased over } \\
\text { the course of the } \\
\text { game. }\end{array}$ & $\begin{array}{l}\text { Financial performance } \\
\text { has varied over the } \\
\text { course of the game but } \\
\text { has not met the course } \\
\text { goal. }\end{array}$ & $\begin{array}{l}\text { Financial performance } \\
\text { has increased in a } \\
\text { positive direction over } \\
\text { the course of the game } \\
\text { and has met or exceeded } \\
\text { the course goal. }\end{array}$ & $\begin{array}{l}\text { Financial performance has } \\
\text { increased in a positive } \\
\text { direction over the course } \\
\text { of the game and has met } \\
\text { or exceeded the course } \\
\text { goal by over } 10 \% \text { or } \\
\text { more. }\end{array}$ & \\
\hline
\end{tabular}

However, there are some pedagogical challenges that should be noted. To create the adaptive behavioralbased learning outcomes described in this paper, the simulation must be 1) integrated as into a holistically designed syllabus with other forms of traditional pedagogy, 2) be competitive with winners and losers, and 3) include multiple, longitudinal periods of decision-making where students or groups of students are required to adapt to controllable and uncontrollable market forces affecting the ongoing success of their business strategies.

\section{CONCLUSION}

This manuscript has focused on an approach to integrating and assessing adaptive behavioral outcomes holistically into business course pedagogy. It also suggests a method and rubric that can be adapted for use in AACSB Assurance-of-Learning assessment related to adaptive decision-making behavior. When used in this context, a computer simulation can be utilized to assess adaptable behavior at various levels of business knowledge and experience. Depending on the level of student, simulations can be used to build behavioral-based learning outcomes through sequential, step-by-step tutelage on a period by period basis. They can also be used to require students to inductively "figure it out" solely based on the application of knowledge and consequences of decisions. The former has been particularly suited to students studying at the undergraduate level, while the latter has proven to be better suited to the graduate business study level. At the graduate level, core interdisciplinary marketing, accounting, finance, and production knowledge is assumed, so the behavioral-based outcome objectives are adapted to include higher level, more complex inter-disciplinary decision-making.

More traditional pedagogy can also be adapted to take into account adaptable behavior outcomes. For example, case studies that are designed with decision-making "rounds" in longitudinal sequence could be adapted to the suggested assessment rubric. Using this method, new decision-making variables requiring ongoing student decision-making adaptation could be introduced into each round of decision-making. Ultimately, cases could be designed with alternative scenario outcomes for each round that build in different directions based on student adaptive behavior to the variables presented each round. This would provide more longitudinal depth to the case study method and build student knowledge through inductive applied decision-making. 


\section{AUTHOR INFORMATION}

David S. Baker is an assistant professor of marketing and international business at the University of Louisiana at Lafayette. Dr. Baker holds a D.B.A. from Grenoble Ecole De Management in Grenoble France as well as an MBA from The Thunderbird School of Global Management. He has over 20 years of professional experience in senior international management. His primary research areas include the contextual utilization of technology in the business environment, cross-cultural marketing and management, and strategic management in international settings. E-mail: dbaker@louisiana.edu, corresponding author.

Geoffrey T. Stewart is the Acadiana Bottling Professor of Marketing and an Assistant Professor of Marketing at the University of Louisiana. Dr. Stewart holds a Ph.D. in Marketing from the University of Tennessee, as well as BS and MBA degrees from the University of Louisiana. His current research focuses on business relationship development, public-private partnerships, and supply chain disruptions. Dr. Stewart's previous publications have appeared in the International Journal of Physical Distribution and Logistics Management, Journal of Business and Industrial Marketing, Marketing Management Journal, The Journal of Business Issues, Research in Higher Education Journal and Equal Opportunities International. E-mail: gstewart@ louisiana.edu

\section{REFERENCES}

1. Aldrich, Clark (2005), Learning by Doing: A Comprehensive Guide to Simulations, Computer Games and Pedagogy in E-Learning and Other Educational Experiences, John Wiley and Sons, New York, NY.

2. Anderson, Phillip H. and Leigh Lawton (2009), "Business simulations and cognitive learning developments, desires and future directions" Simulation and Gaming, 40(2), pp. 193-216

3. Cadotte, Ernest R. (1995), "Business Simulations: The Next Step in Management Training", Selections, 54(2), pp8-16

4. Clarke, Elizabeth (2009), "Learning Outcomes from business simulation exercises: Challenges for the implementation of learning technologies", Education+Training, 50(5/6), pp. 448-459

5. Cohen, Kalman J. and Eric Rhenman (1961), "The Role of Management Games in Education and Research", Management Science, 7(2), pp. 131-166

6. Haskell, Nancy and Donald Beliveau (2010), "Measuring the Soft Side of Achievement of Assurance-ofLearning Objectives', The Business Review, Cambridge, 16(2), December, pp. 16-26

7. Lainema, Tino and Kirsi Lainema (2007), "Advancing Acquisition of Business Know-How: Critical Learning Elements", Journal of Research on Technology in Education, 40(2), pp. 183-198.

8. Michlitsch, J., \& Sidle, M. (2002). Assessing student learning outcomes: A comparative study of techniques used in business school disciplines. Journal of Education for Business, 77(3), 125-130.

9. Prince, Michael J. and Richard M. Felder (2006), "Inductive Teaching and Learning Methods: Definitions, Comparisons, and Research Bases", Journal of Engineering Education, 95(2), pp. 123-138

10. Scherpereel, Christopher M, (2005), "Changing mental models: business simulation exercises", Simulation and Gaming, 36(3), p. 388

11. Senge, Peter M. (1995), The Fifth Discipline: The Art and Practice of the Learning Organization, Doubleday, New York, NY. 